\title{
RESEARCH
}

\section{Insurance Adjudication Simulation Across Multiple Institutions and Levels of Learners}

\author{
Heidi N. Eukel, PharmD, ${ }^{\mathrm{a}}$ Chelsey Llayton, PharmD, ${ }^{\mathrm{b}}$ Apryl N. Anderson, PharmD, ${ }^{\mathrm{c}}$ Jordan M. Ballou, \\ PharmD, ${ }^{d}$ Krista L. Donohoe, PharmD, ${ }^{\mathrm{c}}$ Aaron T. Hunt, PhD, MPH, ${ }^{\mathrm{d}}$ Brittney A. Meyer, PharmD, ${ }^{\mathrm{d}}$ Lauren M. \\ Caldas, PharmD ${ }^{\mathrm{c}}$ \\ ${ }^{a}$ North Dakota State University, School of Pharmacy \\ ${ }^{\mathrm{b}}$ University of Charleston, School of Pharmacy \\ ${ }^{c}$ Virginia Commonwealth University, School of Pharmacy \\ ${ }^{\mathrm{d}}$ University of Mississippi, School of Pharmacy \\ ${ }^{\mathrm{d}}$ South Dakota State University, College of Pharmacy and Allied Health Professions
}

Corresponding Author: Heidi N. Eukel, North Dakota State University, School of Pharmacy, PO Box 6050, Fargo, ND 58108-6050. Tel: 701-231-7602. Email: heidi.eukel@,ndsu.edu

Submitted June 3, 2021; accepted October 15, 2021; ePublished November 2021

Objective. A virtual educational innovation was designed and implemented to simulate insurance processing for student pharmacists. Objectives of this manuscript are to evaluate the impact of a third party payer simulation on student knowledge and confidence and report student perceptions of the activity. Methods. First, second, and third-year pharmacy students at four institutions completed the self-paced simulation. Knowledge was assessed by comparing results of multiple choice questions on the pre- and postassessments and evaluated by Wilcoxon signed rank test. Confidence was assessed by the change in selfreported confidence scale measurements and compared using Chi-squared test.

Results. The simulation had a significant impact on student knowledge. The largest improvement was in P1s with a pre- to post-assessment average score difference (scale 0-100) of 16.55 compared to 7.17 for P2s and 10.23 for P3s. The majority of the knowledge questions demonstrated statistically significant improvement, with variation for certain questions between groups. All groups had significantly improved self-rated confidence in their abilities. Most students agreed that they would recommend this activity to other students $(91.7 \%)$ and it encouraged them to think about the material in a new way $(85 \%)$.

Conclusions. Through an innovative simulation on prescription insurance processing, positive results were seen across all 3 levels of learners. Knowledge assessments significantly improved and student confidence increased across all groups and all confidence questions. Participants recommend this activity to other students and felt it was an effective way to learn about insurance adjudication.

Keywords: community pharmacy, simulation, skills laboratory, insurance, third party payer

\section{INTRODUCTION}

Approximately half of all pharmacists in the United States practice in community-based retail settings, which include chain pharmacy, independent pharmacy, and supermarkets. ${ }^{1}$ At least $50 \%$ of a community pharmacist's time is spent dispensing medications and providing patient counseling, and pharmacists are heavily involved in the insurance claims adjudication process. ${ }^{2}$ Prescription drug claims are reimbursed from a variety of sources including employersponsored plans, private insurance, and Medicare/Medicaid. According to the National Community Pharmacists Association, the percentage of prescriptions filled at independent pharmacies billed to a third party has risen from $44 \%$ in 1990 to $90 \% .^{2}$

Patients rely on pharmacists to correctly submit claims for their prescription insurance benefits. ${ }^{3}$ The Accreditation Council for Pharmacy Education (ACPE) and the Center for the Advancement of Pharmacy Education (CAPE) have included medication use systems management as a necessary skill for pharmacists. ${ }^{4,5}$ Additionally, the more recent Entrustable Professional Activities (EPAs) outline the Practice Manager Domain which includes "determine the patient co-pay" and "ensure that formulary preferred medications are used when clinically appropriate" as example supporting tasks for fulfilling a medication order. ${ }^{6}$

While third-party insurance adjudication is an important process of medication dispensing and patient advocacy, there are no published manuscripts related to this educational topic. In one published poster abstract, simulated 
prescription insurance processing exercises were shown to increase students' confidence compared to traditional lectures, but the full activity description and statistical impact has not been published. ${ }^{7}$ To date, the majority of the literature focuses around services for Medicare Part D plan selection and benefits but overlooks the imperative process of adjudicating prescription third-party payer claims. ${ }^{8-10}$

Adjudication of insurance claims taught in a traditional didactic classroom will likely only reach the lowest level of Bloom's taxonomy (remember and understand). ${ }^{11}$ For students to be prepared for community introductory and advanced pharmacy practice experiences (IPPEs and APPEs), educational content should be focused on the higher level of learning with Bloom's levels at or above the Bloom's level of application. While this concept has not specifically been studied in the literature, it is reasonable to say that insurance adjudication is best learned through simulations as many curricula focus on application of skills for similar community pharmacist roles such as patient counseling, compounding, and dispensing. Simulation within pharmacy education is widely accepted as an effective instructional method to improve student knowledge and confidence, as well as educational outcomes. ${ }^{12-15}$

A key element of student success is formative feedback, which has been demonstrated across application-based simulations and objective structured clinical examinations. ${ }^{16}$ Ryan et al found that "response-oriented and conceptually focused feedback was superior to traditional right/wrong feedback." ${ }^{17}$ Integrated formative step-by-step feedback focuses on improvements in the students' process instead of completion of the task and provides elaborate rationale in manageable units to enhance learning. ${ }^{18}$ Faculty from four institutions saw a need for development of a platform to host a simulation to immerse PharmD student to insurance claim adjudication with individualized, formative feedback embedded in every correct and incorrect answer to further enhance student understanding of key concepts. The objectives of this manuscript are to evaluate the virtual insurance simulation's impact on the participating students' knowledge and confidence and report students' perception of the activity.

\section{METHODS}

Development of the virtual insurance simulation was a collaborative effort by a PGY-2 academic pharmacy resident, fourth-year academic Advanced Pharmacy Practice Experiences (APPE) student, and faculty from four institutions. The simulation was developed based on prescription insurance-related issues seen in the community pharmacy practice setting. The education activity was designed to address high levels of Bloom's Taxonomy, the Entrustable Professional Activities (EPAs) and the Pharmacists Patient Care Process (PPCP) which were linked to the activity's learning objectives (Table 1). ${ }^{6,11,19}$

A PowerPoint slide deck was created with several patient cases and associated multiple-choice questions with hyperlinked answer choices. Based on the choice selected, students would be directed to a slide that said "correct" or "incorrect, try again." Detailed justification was provided for each correct and incorrect choice. If they answered correctly, they would progress to the next question. If they chose incorrectly, they would be directed back to the same question, with unlimited attempts for each question. Probing questions and statements were included for all incorrect choices to guide student critical thinking (Figure 1). Students filled out a worksheet as they went through the PowerPoint slide deck with the same questions which could be turned in for a graded assignment assessed on completion.

The activity was designed to teach students through immediate, formative feedback for correct and incorrect answers as they progressed so that students at any level of previous employment and academic experience could complete it without a didactic lecture component. The formative feedback component for all correct and incorrect choices was embedded with detailed justification so each student received individualized guidance throughout the entirety of the simulation, an added value beyond lecture-based delivery of this educational content. An optional reading from "Medical Insurance for Pharmacy Technicians" was included as a suggested pre-reading. ${ }^{20}$ Given this learn-as-you-go nature, little faculty facilitation was required during the simulation.

The activity took place within a longitudinal pharmacy skills-based laboratory sequence for first-, second-, and third-year (P1, P2, P3) pharmacy students at four institutions. This simulation was aligned in the skills laboratory course at each institution with curricular topics relevant to community pharmacy practice.

To ensure ease of use, the virtual insurance simulation was piloted in skills-based laboratory courses of two Doctor of Pharmacy programs. Fourth-year APPE students at School A tested the activity for completeness, accuracy, and ease of use. P3 students at one institution and P2 students at another then piloted the activity. Students who completed the pilot were asked to provide feedback via an anonymous online survey on the length of the simulation and suggestions for improvement. Based on this feedback, cases were adjusted to ensure P1 students could complete them without prior therapeutics knowledge and directions were provided for making a medication recommendation to a provider, including a sound clip with an example. Updated materials were distributed for implementation in three different class years (P1, P2, P3) across 4 institutions for the 2020-2021 academic year. 
The activity was implemented virtually across all cohorts. The simulation was delivered asynchronously by posting materials to teach institution's learning management system. Materials included the PowerPoint presentation, activity worksheet and key, an insurance formulary for one of the cases, suggested reading citation, and student instructions to post to a learning management system. This study was exempted from full review by South Dakota State University's Institutional Review Board with reliance agreements at the other institutions.

Differences in demographic characteristics between groups were determined by Chi-square test, Friedman's test, and $t$-test. Changes between pre- and post-assessment knowledge scores were evaluated by Wilcoxon signed rank test due to violations of normal distribution. Differences in correct answers were compared for each question for each year of study using Chi-squared test. Differences in mean pre- and post-assessment scores by characteristic were compared using Chi-squared test. Results were considered significant if less than $\mathrm{p}=.05$. Missing values were excluded from analyses and outliers were retained.

A pre- and post-assessment was embedded within the simulation to be completed by students using an electronic survey (QuestionPro). The pre-assessment included questions to gather (1) demographic information and (2) baseline knowledge related to the educational topic. The post-assessment included (1) the same knowledge-based questions, as well as questions addressing (2) students' self-assessment of confidence, and (3) students' perceptions of the learning activity.

The knowledge assessment included 14 multiple choice questions that were developed by the faculty and pilot tested prior to the study. All questions had four answer options and were worth one point for correct answers and zero points for incorrect answers. Answers for the questions were not provided to decrease recall bias. The knowledge assessment captured variations of insurance adjudication problems seen in practice and were created to be similar, but not direct copies of, the problems covered in the form of cases. The total knowledge assessment scores were summed for each student and percentages calculated to compare differences between the pre- and post-student assessments. All knowledge assessment questions were mapped to learning objectives, Bloom's Taxonomy, case description, entrustable professional activities (EPA) alignment, and the Pharmacists' Patient Care Process (PPCP) (Table 1).

Students reported pre- and post-activity self-rated confidence, rated on a scale of 0-100, for 5 questions over their ability to process and handle insurance problems addressed by pharmacists (Table 5). The mean scores were calculated and compared pre- and post- completion of the training module. Additionally, a set of 4 questions were modified from a previously-published educational innovation perception tool and were used to measure overall perceptions of the simulation using a five-point Likert scale ranging from " $1=$ strongly disagree" to " $5=$ strongly agree." 21 Student perceptions were assessed as frequencies and percentages of the Likert scale questions.

\section{RESULTS}

The study participants $(\mathrm{n}=462)$ were grouped into their year in academic study as P1, P2, and P3 students. Table 2 displays the study population characteristics. Overall, there were several significant differences between the participants when comparing by year of study which were expected, such as P3 students were more likely to have completed insurance processing training (31.6\% compared to $19 \%$ for P1 and $28 \%$ for P2). P1 students were less likely to have worked in any pharmacy setting. A total of $88 \%$ of P1 students have worked in any pharmacy, compared to $95 \%$ of the P2 and P3 cohorts $(p<.001)$. Of those student groups who indicated they had processed insurance rejections, there were differences between the groups $(\mathrm{p}=.001)$ with the majority of first year students indicating less than 20 times, while P3 students more frequently indicated more than 100 times. Other differences that were not expected included the P2 students being less likely to have been uninsured and the differences in race and ethnicity among the groups, with the P2 year students more likely to be Caucasian.

The pre- and post-assessments among pharmacy students by year of study (P1, P2, or P3) showed a significant increase in knowledge across all groups for the total assessment score (Table 3). The largest improvement was seen in the P1 cohort. The data for each individual question shows the majority of the 14 knowledge questions demonstrated statistically significant improvement, with variation for certain questions between the groups (Table 4). P1 students displayed significant increases in 10 of the 14 knowledge assessment items, 7 with the P2s, and 8 with the P3 student groups. Significant improvements were seen in the knowledge assessment questions 1, 2, 3, 5, 6 for all groups. Question 9 on determining copay for a patient demonstrated $100 \%$ accuracy from the P1 students in the post-assessment.

Students in all three years were significantly more likely to answer question 4 incorrectly following the completion of the training. For this question, the students were given a case of an antibiotic ear drop with the messaging "Max daily dose exceeded: Max daily dose $=0.5 \mathrm{~mL} /$ day". The correct resolution was to adjust the day supply from 7 days to 10 days per the insurance, even though the prescription read "for 7 days." Of the students, $66.8 \%$ of P1s, 43.8\% of P2s, and $43.2 \%$ of $\mathrm{P} 3 \mathrm{~s}$ chose to call the prescriber for a medication change, instead of the correct answer. 
Additionally, question 7 for both $\mathrm{P} 2$ and $\mathrm{P} 3$ students and question 12 for P2s demonstrated a decrease in correct answers on the post-assessment, although not significantly decreased. Question 7 referred to processing a rosuvastatin prescription with a rejection that read "Prior authorization required. Non-preferred product". Students should have recognized the insurance required an alternative statin medication from the same class; however, many students selected that the entire medication class would require prior authorizations $(27.1 \% \mathrm{P} 2 \mathrm{~s}$ and $20.6 \% \mathrm{P} 3 \mathrm{~s}$ in the post-assessment). $\mathrm{P} 2$ students decreased the number of correct answers for question 12, which focused on a patient acquiring medication through a patient assistance program, from $75 \%$ correct on the pre-assessment to $71.9 \%$ correct on the post-assessment. The majority still chose the correct answer of a patient assistance program, however, the manufacturer coupon (21.9\%) was the next most common chosen answer on the post-assessment.

P1, P2, and P3 cohorts demonstrated significantly different pre-assessment average scores when assessed per question. This difference became insignificant for the post-assessment knowledge questions 1 ( $p=.003 \mathrm{vs} .37), 5$ $(p=<.001$ vs .699), 9 ( $p=.004$ vs .119), and 10 ( $p=<.001$ vs .124). Differences in mean pre-and post-assessment scores by characteristic demonstrated variations for students who previously received formal training in processing insurance rejections or personally processed an insurance rejection. Students reporting previous experience processing insurance rejections had significantly higher pre-knowledge (73.4\% SD 16.9) and post-assessment knowledge (80.16\% SD 12.9) and confidence scores (58.6\% SD 25.3 and 72.91\% SD 20.3), compared to their colleagues without ( $<<.001)$. Within students reporting experience processing insurance rejections, those answering " 20 or more times" had higher means than those with "less than 20 times" across the pre-and post-assessments for both knowledge and confidence $(p<.001)$.

Knowledge questions which focused on the lower level of Bloom's Taxonomy (Application) and early stages of the PPCP and the EPA practice manager's "Fulfill a medication order" demonstrated more significant improvement after the virtual simulation (Table 1). Question 8 and 9, which were linked to PPCP's assessment and plan, were improved for all groups but only significantly for the P1 group. It is important to note that the P2 and P3 students scored high for the pre-assessment making a significant change difficult. Questions rooted in the PPCP's Implement and Monitoring and Evaluation steps and the highest level of Bloom's Taxonomy (Creation) were questions 6 and 13. Each showed an increase, but only 6 had a significant increase.

Pre- and post-confidence self-rating increased significantly among the students in all groups. The largest increases were seen among the P1 students for all indicators. Interestingly, improvements differed by category for the P2 and P3 students. P2 students had higher gains for items 2, 3, and 5, while P3 students had larger increases for items 1 and 4 (Table 5).

Student perception results from the modified perception scale were positive. The majority of students (85\%) agreed or strongly agreed that the virtual insurance simulation encouraged them to think about the material in a new way. Additionally, $91.7 \%$ of the participants agreed or strongly agreed that they would recommend this activity to other students and $87.8 \%$ agreed/strongly agreed that this was an effective way to learn new information. More variation was seen in the students' perception of "I learn better in this format than in a classroom lecture," with $14.4 \%$ in disagreement, $24.8 \%$ neutral, and $60.8 \%$ in agreement. This difference could be attributed to the fact that students are comfortable with lecture-based learning and not necessarily specific to this educational topic or innovation.

\section{DISCUSSION}

The virtual insurance simulation was transferable to multiple institutions, was delivered virtually, and demonstrated an increase in students' knowledge and confidence in all student program years (P1, P2, and P3). The structure allowed students to learn as they proceeded through the cases on the PowerPoint slideshow requiring minimal faculty facilitation. The simulation and associated materials are available for download as article supplements to encourage seamless transferability to all interested faculty at https://tinyurl.com/4cezwpzt. These materials include the complete simulation file (Supplement 1), Student worksheet (Supplement 2), learning management system announcement posting with description of activity (Supplement 3), and additional case materials (Supplement 4). This activity did not require grading and instead provided immediate, formative feedback throughout the simulation.

Participants' knowledge in the overall 14-question knowledge assessment significantly increased between the preand post-assessment for all program years. This may indicate that programs can place the simulation within their curriculum whenever it works best for their program's organization. Students with formal training or IPPE experiences consistently displayed higher knowledge scores (for both pre- and post-assessments) than their peers, and those with more experience displayed higher knowledge scores for the pre- and post-knowledge assessment than those with less experience. Interestingly, group comparisons by question displayed more significant variation during the pre-assessment than the post-assessment on certain questions. This may mean that this activity can help students with no or limited 
experience in claim adjudication attain a similar knowledgebase as their more experienced peers, however, this study was not designed to display that.

Of note, each group displayed worsening scores for certain questions, of which question 4 was significantly worse (Table 4). This question was developed to assess simulation learning objective 1, "Describe third-party entry into an electronic dispensing system. While this learning objective performed well for questions 1 through 3 , question 4 was a practical question on day supply (Table 4). Day supply has been taught in the skills laboratory across multiple institutions to use the duration of therapy (ie, for 7 days) as the day supply since dispensing in the laboratory setting typically assumes cash-paying patients without the ability to process claims. For future interactions, examples of variations from education setting and realities of practice will be included.

Simulation learning objective 2, Identify errors for third-party processing adjudication claims, w aligned with knowledge questions 5, 9, and 10. All student groups significantly improved for question 5, with P1s significantly improving on all questions. The P2 and P3 students improved on question 9 and 10, but with only question 10 being significantly improved for P3s. This variation in significance is largely due to the high scores for the pre-test, with all the post test scores above $97 \%$ for these two questions.

Simulation learning objective 3, Develop resolution for third-party processing adjudication claims rejections, " was assessed with knowledge questions 7, 8,11, 12 and 14. P1s improved significantly on all knowledge questions mapped to this learning objectives with the exception of number 12. P2s only significantly increased for question 11 and P3s only question 11 and 14. Question 7 showed a decrease for P2s and P3s and was a similar extrapolation error with applying a specific case example to a knowledge assessment as seen with question 4. Students were to call the provider and change the medication within the class; however, students chose that a prior authorization would be needed as they had determined in the simulation case. Additional education on determining when a prior authorization or a medication change is appropriate will be included in the future.

Simulation learning objective 4, "Discuss recommendations to the prescriber and/or patient," was assessed with knowledge-question 6 and 13. All student groups improved significantly in question 6 and increased insignificantly for question 13.

Confidence increased across all groups between their pre- and post-assessments for all questions (Table 5). The post-test mean student confidence demonstrates a range of confidence between approximately $50-80 \%$, with $100 \%$ signifying complete confidence. As a pre-APPE simulation, it is not expected that a one-time immersion in third-party claims adjudication would results in $100 \%$ confidence for any level or learner. Student self-reported confidence is not always a predictor of competency. However, when used as an adjunct to competency or knowledge gains, it contributes a critical element to evaluating educational interventions. ${ }^{22}$

Students' perspectives of the educational activity were overall quite positive with only disagreement when students compared simulation over traditional lectures. Nevertheless, still over half of the students were in agreement that they learned better in this format. With $91.7 \%$ of students suggesting this activity for other students, faculty could consider utilizing the virtual insurance simulation with immediate, formative feedback.

This study is not without limitations. The knowledge assessment was created to be similar but with variations seen in practice and not direct copies of the patient cases. However, gaps were made evident between the simulation and the knowledge assessment after the statistical analysis of individual questions. Upon review, these authors suggest future offerings consider additional information on common dispensing adjudication messages. Knowledge and skill retention and IPPE/APPE readiness was not an objective of this study and was therefore not measured. This would be a valuable avenue for future research.

This activity requires no additional cost, minimal faculty resources, and was transferable to multiple institutions. MyDispense is a free system available to all institutions. Future cohorts at each program will continue to utilize this virtual simulation. Programs will see the largest impact on P1 students in education, but adding this education intervention within any portion of the didactic curriculum will benefits both student knowledge and confidence of their skills in insurance adjudication.

\section{CONCLUSION}

The virtual insurance adjudication simulation was implemented virtually across P1, P2, and P3 students at four institutions. Knowledge assessments significantly improved across all three groups of students, while analysis between each question demonstrated variations in student performance. Student confidence increased across all groups and all confidence questions. Participants recommend this activity to other students and felt it was an effective way to learn about insurance adjudication. 


\section{REFERENCES}

1. Pharmacists : Occupational Outlook Handbook: : U.S. Bureau of Labor Statistics. Accessed June 3, 2021. https://www.bls.gov/ooh/healthcare/pharmacists.htm\#tab-3

2. Profile_16 Independent FINAL 071213.pdf. Accessed June 3, 2021. https://aphanet.pharmacist.com/sites/default/files/files/Profile_16\%20Independent\%20FINAL\%20071213.pdf

3. Rudolph NV. Medicare Beneficiary Knowledge of and Experience with Prescription Drug Cards. Health Care Financing Review. 29(1):16.

4. Medina MS, Plaza CM, Stowe CD, et al. Center for the Advancement of Pharmacy Education 2013 Educational Outcomes. Am J Pharm Educ. 2013;77(8). doi:10.5688/ajpe778162

5. Accreditation Council for Pharmacy Education. Accreditation standards and key elements for the professional program in pharmacy leading to the doctor of pharmacy degree. (Standards 2016). Published online 2015.

6. Haines ST, Pittenger AL, Stolte SK, et al. Core Entrustable Professional Activities for New Pharmacy Graduates. AJPE. 2017;81(1):S2. doi:10.5688/ajpe811S2

7. Walker AL_AACP Poster Abstract 2020.docx.

8. Cutler TW, Stebbins MR, Lai E, Smith AR, Lipton HL. Problem-based Learning Using the Online Medicare Part D Plan Finder Tool. Am J Pharm Educ. 2008;72(3):47. doi:10.5688/aj720347

9. Galal SM, Patel RA, Thai HK, et al. Impact of an Elective Course on Pharmacy Students' Attitudes, Beliefs, and Competency Regarding Medicare Part D. AJPE. 2012;76(5):91. doi:10.5688/ajpe76591

10. Hohmann LA, Hastings TJ, McFarland SJ, Hollingsworth JC, Westrick SC. Implementation of a Medicare Plan Selection Assistance Program Through a Community Partnership. AJPE. 2018;82(9):6452. doi:10.5688/ajpe6452

11. Bloom's Taxonomy. Vanderbilt University. Accessed October 3, 2021. https://cft.vanderbilt.edu/guides-subpages/blooms-taxonomy/

12. Lin K, Travlos DV, Wadelin JW, Vlasses PH. Simulation and Introductory Pharmacy Practice Experiences. AJPE. 2011;75(10):209. doi:10.5688/ajpe7510209

13. Ray SM, Wylie DR, Shaun Rowe A, Heidel E, Franks AS. Pharmacy Student Knowledge Retention After Completing Either a Simulated or Written Patient Case. AJPE. 2012;76(5):86. doi:10.5688/ajpe 76586

14. Metzger NL, Chesson MM, Momary KM. Simulated Order Verification and Medication Reconciliation during an Introductory Pharmacy Practice Experience. AJPE. 2015;79(7):96. doi:10.5688/ajpe79796

15. Komperda K, Lempicki K. Effectiveness of a Medication Reconciliation Simulation in an Introductory Pharmacy Practice Experience Course. AJPE. 2019;83(4):6628. doi:10.5688/ajpe6628

16. Gums TH, Kleppinger EL, Urick BY. Outcomes of Individualized Formative Assessments in a Pharmacy Skills Laboratory. AJPE. 2014;78(9). doi:10.5688/ajpe789166

17. Ryan A, Judd T, Swanson D, et al. Beyond right or wrong: More effective feedback for formative multiple-choice tests. Perspect Med Educ. 2020;9(5):307-313. doi:10.1007/s40037-020-00606-z

18. Shute VJ. Focus on Formative Feedback. Review of Educational Research. 2008;78(1):153-189. doi:10.3102/0034654307313795

19. The Pharmacists' Patient Care Process. JCPP. Accessed May 25, 2018. https://jcpp.net/patient-care-process/

20. Medical Insurance for Pharmacy Technicians: 9780073374161: Medicine \& Health Science Books @ Amazon.com. Accessed June 3, 2021. https://www.amazon.com/Medical-Insurance-Pharmacy-TechniciansInstructor/dp/0073374164

21. Eukel HN, Frenzel JE, Cernusca D. Educational Gaming for Pharmacy Students - Design and Evaluation of a Diabetes Themed Escape Room. Am J Pharm Educ. Published online September 8, 2017:ajpe6265. doi:10.5688/ajpe6265

22. Gabbard T, Romanelli F. The Accuracy of Health Professions Students' Self-Assessments Compared to Objective Measures of Competence. Am J Pharm Educ. 2021;85(4):8405. doi:10.5688/ajpe8405 


\begin{tabular}{|c|c|c|c|c|}
\hline $\begin{array}{c}\text { Learning Objectives } \\
\text { (Bloom's Taxonomy } \\
\text { Level)* }\end{array}$ & $\begin{array}{c}\text { Entrustable Professional } \\
\text { Activities (EPA) alignments }\end{array}$ & $\begin{array}{c}\text { Pharmacist } \\
\text { Patient Care } \\
\text { Process (PPCP) }\end{array}$ & Case Descriptions & $\begin{array}{c}\text { Knowledge (K) } \\
\text { and Confidence } \\
\text { (C) Questions } \\
\text { Mapping }\end{array}$ \\
\hline $\begin{array}{l}\text { 1) Demonstrate third-party } \\
\text { entry into an electronic } \\
\text { dispensing system } \\
\text { (Application) }\end{array}$ & $\begin{array}{l}\text { Practice Manager Domain (Fulfill a } \\
\text { medication order): } \\
\checkmark \quad \text { Enter patient-specific } \\
\text { information into an } \\
\text { electronic health or } \\
\text { pharmacy record }\end{array}$ & Collect & $\begin{aligned} & \text { Case } 1 \text { 1: Third-party insurance card processing } \\
& \checkmark \text { Identify provider type by card } \\
& \checkmark \text { Identify correct processing information from } \\
& \text { insurance card } \\
& \text { Case 2: } \text { Medicare insurance processing } \\
& \checkmark \text { Identify correct Medicare card for medication } \\
& \text { processing } \\
& \checkmark \text { Identify correct Medicare card for influenza } \\
& \text { vaccination } \\
& \text { Case 4: } \text { Third-party rejection for coverage terminated } \\
& \circ \quad \text { Input new third-party card information } \\
& \circ \quad \text { Determine Dispense-As-Written (DAW) code } \\
& \text { for a medication claim }\end{aligned}$ & $\begin{array}{l}\mathrm{K} 1, \mathrm{~K} 2, \mathrm{~K} 3, \mathrm{~K} 4 \\
\mathrm{C} 1\end{array}$ \\
\hline $\begin{array}{l}\text { 2) Evaluate and solve errors } \\
\text { for third-party processing } \\
\text { adjudication claims } \\
\text { (Evaluation, Creation) }\end{array}$ & $\begin{array}{l}\text { Practice Manager Domain (Fulfill a } \\
\text { medication order): } \\
\checkmark \quad \text { Determine the patient co- } \\
\text { pay or price for a } \\
\text { prescription } \\
\checkmark \quad \text { Ensure that formulary } \\
\text { preferred medications are } \\
\text { used when clinically } \\
\text { appropriate }\end{array}$ & Assess & $\begin{array}{l}\text { Case 5: Preferred formulary substitution } \\
\checkmark \quad \text { Determine alternatives based on a third-party } \\
\text { formulary list } \\
\text { Case 6: Third-party Deductibles } \\
\quad \text { Interpret third-party messaging } \\
\circ \quad \text { Interpret patient-copay } \\
\text { Case 7: Third-party messaging- Step Therapy indicated } \\
\checkmark \quad \text { Interpret third-party messaging }\end{array}$ & $\begin{array}{l}\mathrm{K} 5, \mathrm{~K} 9, \mathrm{~K} 10 \\
\mathrm{C} 2\end{array}$ \\
\hline $\begin{array}{l}\text { 3) Develop resolution for } \\
\text { third-party processing } \\
\text { adjudication claims } \\
\text { rejections (Creation) }\end{array}$ & 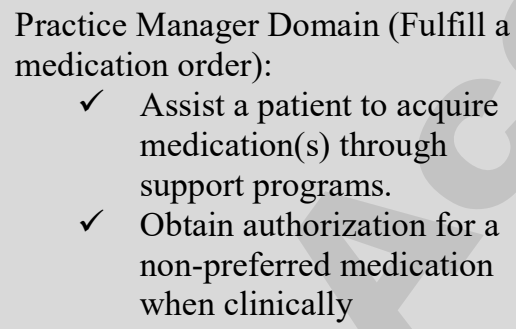 & Plan & $\begin{array}{l}\text { Case 3: Medicare and Medicaid Coverage } \\
\checkmark \quad \text { Determine funding sources between Medicare } \\
\quad \text { and Medicaid } \\
\checkmark \quad \text { Identify billing order for dual coverage } \\
\text { Case 6: Third-party Deductibles } \\
\checkmark \quad \begin{array}{l}\text { Assist patients to interpret their coverage gaps } \\
\text { or deductibles }\end{array}\end{array}$ & $\begin{array}{l}\mathrm{K} 7, \mathrm{~K} 8, \mathrm{~K} 11, \\
\mathrm{~K} 12, \mathrm{~K} 14 \\
\mathrm{C} 3\end{array}$ \\
\hline
\end{tabular}


Case 7: Processing a prior authorization and patient support programs

$\checkmark$ Determine therapeutic alternative for a nonpreferred product

$\checkmark$ Assist patient to acquire medications through support programs

4) Formulate

recommendations to the

prescriber and/or patient

(Creation)
Interprofessional Team Member

Domain (Collaborate as a member

of an interprofessional team)

$\checkmark$ Communicate a patient's

medication-related

problem(s) to another

health professional

$\checkmark \quad$ Use setting appropriate communication skills when interacting with others

Patient Care Domain (Implement a care plan in collaboration with the patient, caregivers, and other health professionals.)

$\checkmark \quad$ Educate a patient regarding the appropriate use of a new medication, device to administer a medication, or self-monitoring test.

*Bloom's Taxonomy ${ }^{11}$

$\mathrm{K}=$ knowledge assessment question

$\mathrm{C}=$ confidence assessment question 
Table 2. Study Population Characteristics $(n=462)$

\begin{tabular}{|c|c|c|c|c|}
\hline Characteristic & P1 & $\mathbf{P 2}$ & P3 & p \\
\hline \multicolumn{5}{|l|}{ Age } \\
\hline What is your age? (mean, SD) & $22.06(2.91)$ & $22.54(3.16)$ & $25.02(2.84)$ & $\mathbf{p}<.001$ \\
\hline \multicolumn{5}{|l|}{ With which gender do you identify? } \\
\hline Male & $27.96 \%$ & $35.42 \%$ & $32.26 \%$ & \multirow[t]{4}{*}{$\mathrm{p}=.737$} \\
\hline Female & $71.09 \%$ & $64.58 \%$ & $67.10 \%$ & \\
\hline Prefer not to say & $0.47 \%$ & $0.00 \%$ & $0.65 \%$ & \\
\hline Other & $0.47 \%$ & $0.00 \%$ & $0.00 \%$ & \\
\hline \multicolumn{5}{|l|}{ Were you born in the US? } \\
\hline Yes & $89.10 \%$ & $93.75 \%$ & $86.50 \%$ & \multirow[t]{3}{*}{$\mathrm{p}=.195$} \\
\hline No & $10.90 \%$ & $6.25 \%$ & $13.50 \%$ & \\
\hline Prefer not to say & $0.00 \%$ & $0.00 \%$ & $0.00 \%$ & \\
\hline \multicolumn{5}{|c|}{ Have you or a close family member experienced a serious health condition? } \\
\hline Yes & $63.51 \%$ & $56.25 \%$ & $72.90 \%$ & \multirow[t]{3}{*}{$\mathrm{p}=.089$} \\
\hline No & $35.07 \%$ & $42.71 \%$ & $25.81 \%$ & \\
\hline Prefer not to say & $1.42 \%$ & $1.04 \%$ & $1.29 \%$ & \\
\hline \multicolumn{5}{|l|}{ ฮี Are you currently, or have you ever been uninsured? } \\
\hline Yes & $21.30 \%$ & $6.30 \%$ & $28.40 \%$ & \multirow[t]{3}{*}{ p 0.001} \\
\hline No & $78.70 \%$ & $93.80 \%$ & $70.30 \%$ & \\
\hline Prefer not to say & $0.00 \%$ & $0.00 \%$ & $1.30 \%$ & \\
\hline \multicolumn{5}{|c|}{ WुWhat type of pharmacy, if any, have you worked/volunteered in (select all that apply)? } \\
\hline Community pharmacy & $70 \%$ & $83 \%$ & $86 \%$ & $\mathbf{p}=\mathbf{0 0 1}$ \\
\hline Hospital pharmacy & $30 \%$ & $24 \%$ & $46 \%$ & $\mathbf{p}<.001$ \\
\hline Ambulatory care clinic & $3 \%$ & $1 \%$ & $20 \%$ & $\mathbf{p}<.001$ \\
\hline None & $22 \%$ & $5 \%$ & $5 \%$ & $\mathbf{p}<.001$ \\
\hline \multicolumn{5}{|c|}{ On average, how many hours per week do you work at a pharmacy? } \\
\hline During the academic year, mean (SD) & $6.14(8.89)$ & $9.40(8.21)$ & $9.45(5.97)$ & $\mathbf{p}<.001$ \\
\hline During summer break, mean (SD) & $21.31(18.11)$ & $31.04(14.60)$ & $27.99(14.08)$ & $\mathbf{p}<.001$ \\
\hline How many months have you worked? Mean (SD) & $13.86(14.08)$ & $23.46(20.21)$ & $37.39(24.08)$ & $\mathbf{p}<.001$ \\
\hline \multicolumn{5}{|c|}{ Have you received formal training for processing insurance rejections? } \\
\hline Yes & $19.00 \%$ & $28.10 \%$ & $31.60 \%$ & $\mathbf{p}=\mathbf{0 1 7}$ \\
\hline \multicolumn{5}{|c|}{ ర్ Have you personally processed a community pharmacy insurance rejection as an intern or on IPPE? } \\
\hline Yes & $39.30 \%$ & $79.20 \%$ & $71.60 \%$ & $<.001$ \\
\hline \multicolumn{5}{|c|}{ Approximately how many times have you processed insurance rejections? } \\
\hline Less than 20 times & $30.1 \%$ & $21.1 \%$ & $17.1 \%$ & $=.012$ \\
\hline 20 to 100 times & $39.8 \%$ & $50.0 \%$ & $34.2 \%$ & \\
\hline More than 100 times & $30.10 \%$ & $28.90 \%$ & $48.60 \%$ & \\
\hline \multicolumn{5}{|l|}{ Race/Ethnicity } \\
\hline White & $68.2 \%$ & $91.7 \%$ & $61.9 \%$ & $\mathbf{p}=\mathbf{0 0 1}$ \\
\hline Hispanic, Latino or Spanish origin & $2.8 \%$ & $0.0 \%$ & $2.6 \%$ & \\
\hline Black or African American & $7.1 \%$ & $1.0 \%$ & $7.7 \%$ & \\
\hline Asian & $15.6 \%$ & $5.2 \%$ & $24.5 \%$ & \\
\hline American Indian or Alaska Native & $0.5 \%$ & $0.0 \%$ & $0.0 \%$ & \\
\hline Middle Eastern or North African & $2.8 \%$ & $1.0 \%$ & $0.6 \%$ & \\
\hline Native Hawaiian or Other Pacific Islander & $0.0 \%$ & $0.0 \%$ & $0.0 \%$ & \\
\hline Some other race, ethnicity or origin & $2.4 \%$ & $1.0 \%$ & $1.3 \%$ & \\
\hline Prefer not to say & $0.5 \%$ & $0.0 \%$ & $1.3 \%$ & \\
\hline
\end{tabular}


Table 3. Mean Student Performance the Knowledge Pre- and Post-Assessment by Pharmacy Student Year $\left(0-100^{\mathrm{a}}\right)$

\begin{tabular}{cccccc}
\hline & $\begin{array}{c}\text { Pre-Test } \\
\text { Mean (SD) }\end{array}$ & $\begin{array}{c}\text { Post-Test } \\
\text { Mean (SD) }\end{array}$ & Difference & $\begin{array}{c}\text { Standardized } \\
\text { Test Statistic }\end{array}$ & $\boldsymbol{p}$ value \\
\hline $\begin{array}{c}\text { P1 } \\
(\mathrm{N}=211)\end{array}$ & $54.88(19.91)$ & $71.43(14.34)$ & 16.55 & 10.375 & $<.001^{*}$ \\
$\begin{array}{c}\mathrm{P} 2 \\
\mathrm{~N}=96)\end{array}$ & $66.22(15.97)$ & $73.39(12.69)$ & 7.17 & 6.84 & $<.001^{*}$ \\
$\begin{array}{l}\mathrm{P} 3 \\
\mathrm{~N}=155)\end{array}$ & $70.92(18.24)$ & $81.15(14.58)$ & 10.23 & 8.534 & $<.001^{*}$ \\
\hline
\end{tabular}

*Wilcoxon signed rank test was used to determine significance, defined as $p<.05$, between the pre- and post- scores for each pharmacy student year.

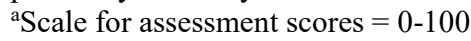

P1=First-year Doctor of Pharmacy students; P2=Second-year Doctor of Pharmacy students; P3=Third-year Doctor of Pharmacy students 


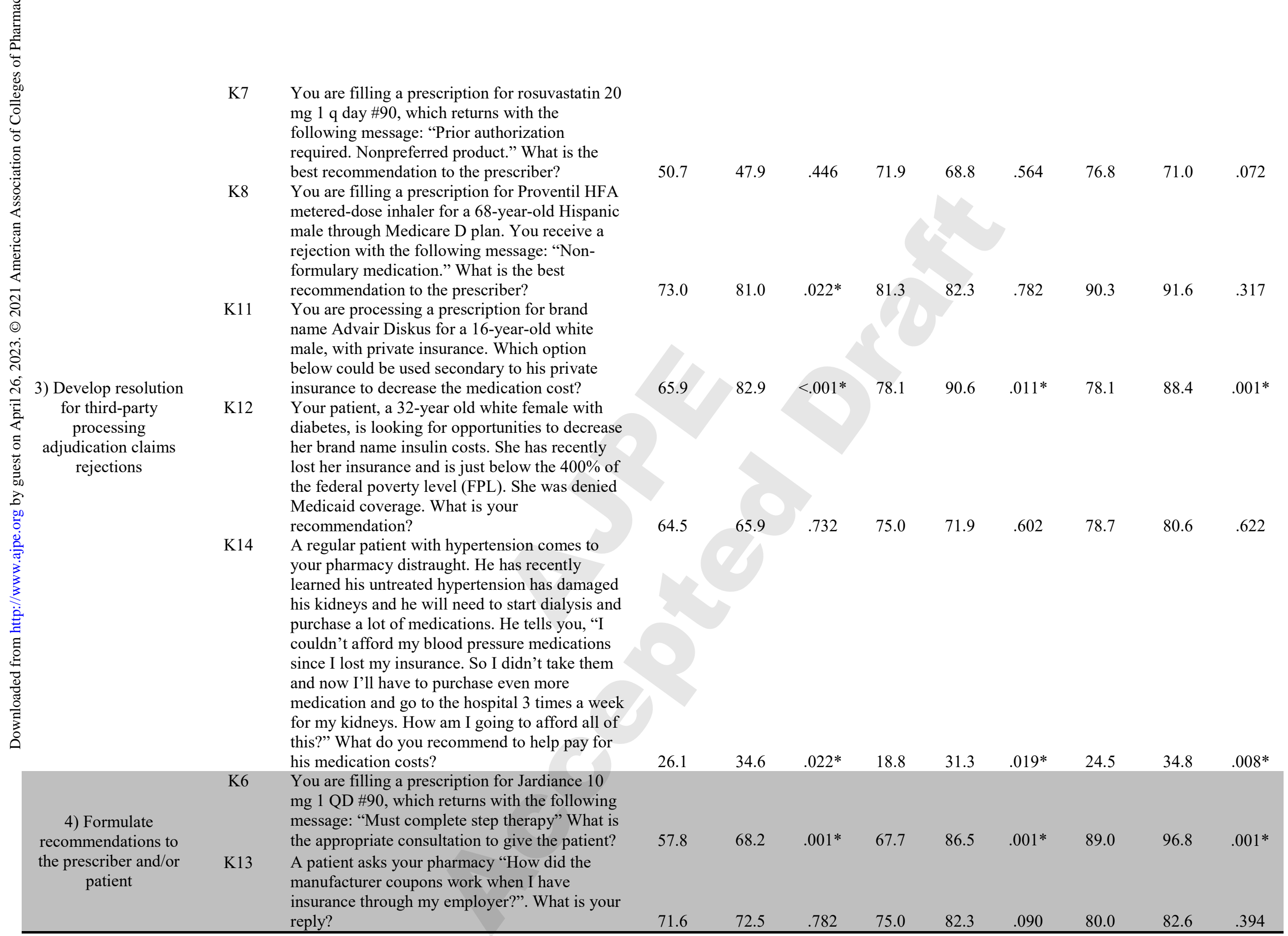


P1=First-year Doctor of Pharmacy students; P2=Second-year Doctor of Pharmacy students; P3=Third-year Doctor of Pharmacy students; DAW=Dispense as Written; $\mathrm{QD}, \mathrm{q}$ day=every day; $\mathrm{mL}=$ milliliter; $\mathrm{mg}=$ milligram; $\mathrm{AC}=$ before meals; $\mathrm{HFA}=$ hydrofluoroalkane 
Table 5. Change in Mean Student Confidence ${ }^{ \pm}$in Processing Insurance Rejections Pre- and Post-Assessment for the Insurance CYOA Simulation by Pharmacy Year

\begin{tabular}{ccccc} 
Pre-Test & Post-Test & & Standardized & \\
$\mathrm{M}(\mathrm{SD})$ & $\mathrm{M}(\mathrm{SD})$ & Difference & Test Statistic & $p$ value \\
\hline
\end{tabular}

Enter third-party information into the appropriate fields for dispensing

$\mathrm{P} 1(\mathrm{~N}=209)$

$\mathrm{P} 2(\mathrm{~N}=96)$

P3 $(\mathrm{N}=152)$

Identify insurance processing problems

$\mathrm{P} 1(\mathrm{~N}=209)$

$\mathrm{P} 2(\mathrm{~N}=96)$

P3 $(\mathrm{N}=152)$

Resolve insurance rejections

$\mathrm{P} 1(\mathrm{~N}=209)$

$\mathrm{P} 2(\mathrm{~N}=96)$

P3 $(\mathrm{N}=152)$

Make a recommendation for alternative treatment to a provider based on the insurance rejection

$$
\begin{aligned}
& \mathrm{P} 1(\mathrm{~N}=209) \\
& \mathrm{P} 2(\mathrm{~N}=96)
\end{aligned}
$$$$
\text { P3 }(\mathrm{N}=152)
$$

Communicate third-party processing adjudication claim information to a patient

$\mathrm{P} 2(\mathrm{~N}=96)$

P3 $(\mathrm{N}=152)$
$\mathrm{P} 1(\mathrm{~N}=209)$

$\begin{array}{ccccc}47.5(39.3) & 73.5(27.12) & 26 & 10.18 & <.001^{*} \\ 67(35.25) & 80.3(25.03) & 13.3 & 6.109 & <.001^{*} \\ 65.7(37.09) & 79.3(24.49) & 13.6 & 7.859 & <.001^{*} \\ & & & & \\ 32.5(31.6) & 60.8(25.95) & 28.3 & 11.393 & <.001^{*} \\ 47.5(30.03) & 65.9(23.15) & 18.4 & 7.57 & <.001^{*} \\ 53.2(32.4) & 70.5(25.68) & 17.3 & 9.176 & <.001^{*} \\ & & & & \\ 29.1(30.49) & 56.8(26.56) & 29.5 & 11.434 & <.001^{*} \\ 42.5(29.42) & 59.6(25.69) & 17.1 & 7.221 & <.001^{*} \\ 49.1(32.2) & 67.5(26.88) & 18.4 & 9.232 & <.001^{*}\end{array}$

$\begin{array}{ccccc}23.8(25.97) & 54.3(26.85) & 26 & 11.642 & <.001^{*} \\ 34.8(28.97) & 57.9(27.76) & 23.1 & 7.875 & <.001^{*} \\ 50.2(30.36) & 70.5(24.45) & 20.3 & 9.195 & <.001^{*}\end{array}$

\begin{tabular}{lllll}
$50.2(30.36)$ & $70.5(24.45)$ & 20.3 & 9.195 & $<.001^{*}$ \\
& & & & \\
& & & & \\
$30.8(31.81)$ & $59.4(28.52)$ & 28.6 & 11.134 & $<.001^{*}$ \\
$49.8(31.98)$ & $67.6(25.27)$ & 17.8 & 6.854 & $<.001^{*}$ \\
$55.3(35.31)$ & $72.5(27.06)$ & 17.2 & 9.042 & $<.001^{*}$ \\
\hline
\end{tabular}

*Wilcoxon signed rank test was used to determine significance, defined as $p<.05$, between the pre- and post- scores for each pharmacy student year.

${ }^{ \pm}$Confidence questions all began with "On a scale of 0 to 100, with 0 indicating no confidence and 100 indicating complete confidence, what is your self-rated confidence in your ability to:"

P1=First-year Doctor of Pharmacy students; P2=Second-year Doctor of Pharmacy students; P3=Third-year Doctor of Pharmacy students 
Figure 1. Insurance Choose-Your-Own-Adventure (CYOA) Simulation Activity Design

\section{Student opens \\ PowerPoint which \\ is saved in show \\ mode (.ppsx)}

Introduction slides with instructions for clicking on the hyperlinked arrows or answer choices to progress ${ }^{*}$
If they click on a correct answer

Slide says "That is correct" with a supporting statement explaining why it is correct. The student then clicks on an arrow at the bottom of the slide
If they click on an incorrect answer

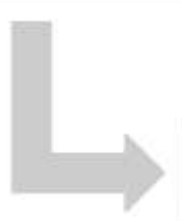

Slide says "That is incorrect" with a suggestion to reconsider the question and additional prompting questions.

The student then clicks on "Let's try again"

"Hyperlinks are created by highlighting the text you desire to be linked, click on "insert", "link", "this document", then select the slide you want the text to be hyperlinked to. 